\title{
sciendo
}

\section{Impacts of the Transformation to Industry 4.0 in the Manufacturing Sector: The Case of the U.S.}

\author{
Katarina ROJKO, Nuša ERMAN \& Dejan JELOVAC \\ Faculty of Information Studies in Novo mesto, Ljubljanska 31a, 8000 Novo mesto, Slovenia, \\ katarina.rojko@fis.unm.si, nusa.erman@fis.unm.si \& dejan.jelovac@fis.unm.si
}

\begin{abstract}
Background and purpose: The transformation to Industry 4.0 increases the number of robots installed within industries, which brings great shifts in industrial ecosystems. For this reason, our research goal was to analyze the key performance indicators to investigate the economic and social sustainability of the changes in production. Methodology: The combination of official (World Bank, U.S. Bureau of Labor Statistics) and publicly available (Federal Reserve Economic Data, Industrial Federation of Robotics) data was used for statistical data processing, including comparison, correlation, cross-correlation and vector autoregression analysis, to present the past developments and also to predict future trends within the U.S. manufacturing sector.

Results: In contrast to robust industry robotization observed in the 2008-2018 period, the share of manufacturing output and employment declined. Nonetheless, the vector autoregression model forecast shows, that the U.S. manufacturing sector has arrived at a turning point, after which robotization can increase employment and labor productivity of workers, while also stimulating further growth of their education levels.

Conclusion: The transition to Industry 4.0 has a major impact on increasing demands for new knowledge and skills for increased productivity. Accordingly, forecasted growths of analyzed manufacturing indicators suggest that negative impacts of robotization in the recent past were only temporary, due to the entrance to the Industry 4.0 era. Nonetheless, additional policies to support sustainable industry development are required.
\end{abstract}

Keywords: Industry transformation, Robotization, Industrial output, Labor productivity, Employment, Education level, Industry 4.0, Industry 5.0

\section{Introduction}

This paper focuses on the recent transformation of industry, specifically the performance of the manufacturing sector as the most robotized sector, in light of the process of robotization. Namely, based on literature review and initial data processing we noted that robotization has been accelerating during the transformation to Industry 4.0, while the increased number of robots within the industry has been having mostly negative impacts on the economic and social indicators. For this reason, our research goal was to analyze some of the key performance indicators to investigate economic and social sustainability of produc- tion. Particularly, we aimed to investigate the first two of the concrete and measurable goals that are described as challenges and opportunities of Industry 4.0 production (Gianelle et al., 2016): economic sustainability of production, social sustainability of production, production of future products, and environmental sustainability of production.

This paper intends to provide clear insight into the current developments within Industry 4.0 transformation, due to the inconsistency within the existing literature, some highlighting positive effects of robotization, while others, negative ones. Namely, in some reports (e.g., in WEO, 2018a) only positive consequences of Industry 4.0 are put to the front. On the other hand, there are also negative

Received: 29th May 2020; revised: 30th August 2020; accepted: 23th September 2020 
views detected in the literature (e.g., in Compagnucci et al., 2019). Based on an initial analysis of certain economic indicators, social indicators, and considering ethical consequences, we first shared negative views. Namely, the recent transition to Industry 4.0 did not bring the expected outcomes, as revealed by, for example, the U.S. Bureau of Labor Statistics (2019a), while it brought great changes in society (claimed by e.g., Johannessen, 2018). Furthermore, it is predicted that all tasks that are highly manual and routine will soon be automated, while artificial intelligence (AI) and robots might present an existential threat to the human role in industry.

In contrast, governments stimulate and supply funds for investments in advanced technologies, including robots; they can also provide "safety nets" to enable social sustainability (in the form of e.g., National Robot Initiative 2.0) of production. For this reason, it is also necessary to determine whether the stimulus and funds are (or will be) achieving their purpose. Our motivation was hence also to determine when (if) we can expect positive outcomes of investments in robotization.

To analyze recent economic and social indicators for the manufacturing sector, we used official data on output, employment, labor productivity, education level change and the Industrial Federation of Robotics (IFR) data on the number of shipped industrial robots ${ }^{1}$. Based on the combination of these data, we presented new associations during the past period of Industry 4.0 and calculated the expected future developments.

The following chapter of the paper includes a literature review, introducing some background views on the transition to Industry 4.0. The third chapter describes our research goal and sets out the research questions, while the fourth presents the data and the research methods we used. The next two chapters present data analysis and summarize our key findings. The last chapter puts forward a critical view on certain literature from the field of research and discusses the possibilities for further human-friendly industry transformation. It also includes considerations about the options for the integration of human capabilities with technology, as they cannot be disregarded within this scope.

\section{Literature Review}

Due to current megatrends (globalization, global knowledge society, technology advancements and resource scarcity), the manufacturing sector is being transformed on the basis of innovations that are available and offer competitive advantages. For this reason, the research priorities of Industry 4.0 are the following: efficient use of resources, customer-focused production, advanced production processes, digital and virtual factories, flexible and smart production systems, mobility, collaboration and human-oriented production (Gianelle et al., 2016).

Smart manufacturing is the central element of the Industry 4.0 concept (Kagermann et al. in Frank et al., 2019). Compared to traditional production, smart factories, which arose within Industry 4.0, are more efficient, produce better quality products, and enable time and cost savings. Smart factories, primarily at the level of processes, change how production plants operate to the extent that all dependent production processes are transparent and combine the virtual and the physical (EFFRA, 2016). The products, resources and processes of the smart factory go into the composition of virtual-physical systems in which materials efficiently move through the production process from the supplier to the finished product and further to the customer. Smart factories combine their solutions for sharing and monitoring, based on a comprehensive integration of manufacturing facilities and technologies. For this reason, Jerman et al. (2020) identified the following key competencies needed by workers in smart factories (from the automotive industry): ICT and technical skills, innovation and creativity, openness to learning, adaptability, and various soft skills.

The recent technology focus in the manufacturing sector is directed toward factories of the future. Factories of the future are raising the level of robotization and are linking knowledge and creativity, enabling increases of added value per employee, and new market opportunities (World Economic Forum, 2018a). However, the integration of technological solutions requires a commitment to the comprehensive exchange of business and production information, based on which it is possible to increase the efficiency and optimization of all production processes: from identifying market needs, planning, modeling and manufacturing a new product, to planning production resources, logistics, and stock management (Gianelle et al.,

\footnotetext{
'The term "industrial robots" is based on the definition of the International Organization for Standardization (ISO 8373): an "automatically controlled, reprogrammable multipurpose manipulator programmable in three or more axes". Industrial robots can be classified according to mechanical structure: articulated, cylindrical, linear (including cartesian and gantry), parallel. or SCARA robots (IFR, 2020).

${ }^{2}$ Frank et al. (2019) separate Industry 4.0 technologies into two main layers: the first is the front-end, which comprises the four main dimensions of Industry 4.0: smart manufacturing (including AI among others), smart products, smart supply chain and smart working, each of them representing a specific subset of technologies; the second layer is base technologies, which are those that provide connectivity and intelligence to the front-end technologies (IoT, Cloud, Big Data and Analytics).
} 
2016).

Many companies have already applied Industry 4.0 technologies ${ }^{2}$ and processes, but several authors warn about current threats of this fourth industrial revolution in the form of economic and social crises, which are, according to Johannessen (2018), ingredients for a social storm. There are also other problems put forward, such as decreased collected labor taxes, as there is no tax and also no social contributions (Bottone, 2018), and other costs related to robots replacing human workers. There are also mixed views regarding, for example, a robot tax would hamper "freeing up" labor and sustain tension on the labor market in economies with labor scarcity (Vermeulen et al., 2020), but it is advised in economies with labor surplus.

Robots replacing humans in essential sectors reduce or eliminate employees' social benefits and pensions, creating social disruption (Lakshmia and Bahlib, 2020). Job security is threatened by a growing number of robots that take over even the most underpaid jobs (Johannessen, 2018). All the routine-based and repetitive tasks, both in manufacturing and service-oriented professions, will be threatened (Lima, 2017). Moreover, robotization and informatization may even contribute to a dissolution of the middle class (Davidow and Malone, 2014 and Chiacchio et al., 2018), while we should also consider the ageing of the workers lowering their productivity in some workplaces (e.g., machine operators and assemblers) (Aiyar et al. in Bogataj et al., 2019). Therefore, this development needs to be regulated on national and transnational levels. Otherwise, employment in the manufacturing sector can be reduced dramatically, such as in the 1970s when many of the textile workers in the OECD area were made redundant in less than one year (Hienstra-Kupeus and Van Voss, 2010). Moreover, as Abramova and Grishchenko (2020) state: "Policy-makers should take into account the transition of labor from old to new jobs, reduce the period of adaptation, and likewise prepare education and training system for acquiring skills for the utilization of new technologies."

The rapid advancements in manufacturing technology and in information and communication technologies require an intense and continuous update of workers' knowledge, which is essential for their integration and smooth adaptation into industrial working practices (Lindeberg, 2018). Governments should require and encourage enterprises to organize skills-training courses and assist them to adapt to new technologies (Guoping et al., 2017), namely a rapid development of technology enables changes in industry as a whole, and the industry's focus moved to the funding of advanced technological solutions to increase outputs and productivity.

Although Acemoglu and Restrepo (2017) demonstrated high and robust negative effects of robotization on employment and wages, and Compagnucci et al. (2019) used IFR data to demonstrate that the introduction of ro- bots plays a key role in slowing down human labor and compensation growth, while Cho and Kim (2018) used IFR data for the multiple regression considering the triangular relationship of employment-working-hours-wages, to show that job destruction due to robotization is not yet very remarkable. In contrast, Cséfalvay (2020) claims "Recent studies clearly show that robotization is associated with economic growth and productivity gains."

Josefsson in Lindeberg (2018) stated: "Robots are now everywhere, except in the productivity statistics", having in mind that robots do not have a positive impact on productivity, which can be regarded as the contemporary productivity paradox. Also, Lakshmia and Bahlib (2020), stating: "While robots and AI researchers advocate their significant role in productivity boost, job creation, wage increment and accelerated performance, such promises are not evident in the immediate future," explain the observed discrepancies through the modern productivity paradox.

While Glaser and Molla (2017) argue that more robots mean fewer jobs, the IFR (2017) has a different opinion, arguing: "Robots substitute labor activities but do not replace jobs." and "Robots increase productivity and competitiveness." Also, the Future of Jobs 2018 survey (UK Parliament, 2018) indicates that new technologies create more jobs and new industries. However, it is not clear whether new technologies create more or fewer jobs than these technologies have eliminated.

Some industrial robots can be very expensive, due to advantages including accuracy and productivity, but robots are still generally considered to be a cheaper workforce, which additionally provokes the worry and uncertainty of workers. Such concerns are also derived from the fact that changes in society can happen much slower than changes in technology and that people cannot compete with robots in the speed of data storage, capacity and retrieval of data (Rojko and Jelovac, 2018). People also cannot compete with technological solutions and robots in many other things: power, precision, ability to work under difficult conditions, and similar factors.

As Šimek and Šperka (2019) quote in their case study: "The development of IT capacity and overall technology will move forward to a state where robots will not only execute the workflow but also assign the work across the company to both robots and humans." The central ethical concern of the transformation to Industry 4.0 is the decreasing need for human engagement and the lack of commitment to consider moral aspects. In fact, installed industry robots replace human workers, which leads to the devaluation of human work and its meaning.

Human workers are afraid that AI and robots can become an existential threat to their existence in industrial processes. However, there are advocates of use and development of AI; Wilson (2017) argues that in the longer perspective the technical evolution, including robots, will serve us all, and Hendler (2017) claims "Humans working 
together with smart machines will be able to do better than either one of them can do alone."

In response to ethical considerations, nine top issues in AI were outlined (Bossemann, 2016): unemployment, inequality, humanity, artificial stupidity, racist robots, security, evil genius, singularity, and robot rights. For our research topic, unemployment, inequality, and humanity are ranked as the top issues, while due to the risk of uncontrolled development of AI, even the World Economic Forum (2018b) facing an automated future, asked: "What moral framework should guide us?"

Supporters of the human role in industry believe that the further transformational goal should be to return jobs to people, but they will have to co-operate, communicate, and interact with advanced technological systems, including robots. However, this poses questions about the ability of AI to apply ethical, cultural and moral norms of modern societies. Specifically, in addition to the above-mentioned concerns over robotization and AI, there are also other impacts; for example, study results of Guo et al. (2019) suggest that humanoid robot's emotional behaviors can evoke significant emotional responses among users. Accordingly, as already widely acknowledged, Putilo et al. (2020) claim that the mass robotization of the manufacturing and service sectors requires solving the problems of the necessity of introducing the status of electronic personality to intelligent robots, defining their legal capacity in the civil, labor, and other fields of law.

The different opinions presented above show the inconsistency within the literature and provide a blurry picture of the current transformation of industry. Moreover, since governments stimulate and provide funds for investments in advanced technologies, it is necessary to determine whether those stimulus and funds are (or will be) achieving their purpose and if economic and social sustainability (as two of the most important goals of Industry 4.0 according to Gianelle et al. (2016)) of the production are viable outcomes of the recent industry robotization or not.

\section{Research goal and research questions}

Addressing the challenges of transformations within Industry 4.0 should be a major part of the research in this field, as the effects of robotization are currently not clear. For this reason, our research goal was to analyze the key performance indicators to investigate the economic and social sustainability of production. We used the combination of the official and publicly available data to present developments within the past researched period and to calculate further trends.

We, therefore, set the following research questions:

1)How do employment and output change in the man- ufacturing sector in relation to the industry as a whole?

2)What were the impacts of robotization on employment and labor productivity in manufacturing during the period of entrance to Industry 4.0?

2.1)How is the impact of robotization reflected in employment and labor productivity in manufacturing?

3)How did the employees' education level change during the period of manufacturing entrance to Industry 4.0?

3.1)Is the impact of robotization reflected in the change of education level of employees in manufacturing?

4)What are the expected future interrelated developments of manufacturing labor productivity, employment, education level and robotization?

In the next section, we present the methodology with which we made comparisons and calculations to answer the above-listed research questions.

\section{Methods}

We used official and publicly available data to answer our research questions, as such data allow the highest reliability and lead to solid conclusions. An analysis and statistical data processing of the U.S. Bureau of Labor Statistics (2019a, 2019b and 2019c), the Federal Reserve Economic (2018), and World Bank (2019) data, combined with publicly available IFR (2018b and 2019) data and sources, enabled us to develop an alternative view on the current transformation of the industry ecosystem.

We focused on the data for the period between 2008 and 2018. We started by presenting the data on employment and output in U.S. industry as a whole, compared to the same data for the U.S. manufacturing sector, as well as the predicted growth thereof in the forthcoming 10-year period. In the next stage of our analysis, we focused on multiple time-series data containing the number of industrial robot shipments, labor productivity in the manufacturing sector, employment and employees' education level in manufacturing. Here, the labor productivity is measured as the amount of goods and services produced according to the number of hours worked to produce those goods and services (U.S. Bureau of Labor Statistics, 2019b), both in the manufacturing sector.

We first outlined the number of industrial robot shipments and employment in manufacturing and compared them to labor productivity in the manufacturing sector. Afterwards, we also studied general education trends vs. industrial robot shipment. In both cases, the significances of trends as a function of time were tested using regression analysis and t-tests.

Following the demonstrated trends, we further investigated the association between the observed time-series data. On the one hand, we calculated the correlation between labor productivity in the manufacturing sector and the number of industrial robot shipments, as well as be- 
tween labor productivity and the number of employees in manufacturing. On the other hand, we also analyzed the association between education level change and the number of industrial robot shipments. To do so, we used cross-correlation analysis, which, besides quantifying the immediate correlation between the two time series, enables assessing the responsiveness of one time series to the other, by simultaneously taking into account the time dimension ( $\mathrm{t}$ ). The cross-correlations are calculated as a nor-

$$
r_{x y}=\frac{\sigma_{x y}(T)}{\sqrt{\sigma_{x x}(0) \sigma_{y y}(0)}}=\frac{\frac{1}{N-1} \sum_{t=1}^{N}\left(x_{t-T}-\mu_{x}\right)\left(y_{t}-\mu_{y}\right)}{\sigma_{x x}(0) \sigma_{y y}(0)}
$$

malized version of the cross-covariance function (Shumway and Stoffer, 2017):

where $\mathrm{xt}$ and $\mathrm{yt}$ are the observed time series with $\mathrm{N}$ data points, $\mu \mathrm{x}$ and $\mu \mathrm{y}$ are their means, $\sigma \mathrm{xx}(0)$ and $\sigma \mathrm{yy}(0)$ are their variances, T represents a time lag, and $\sigma x y(T)$ is the cross-covariance function between the observed time series at lag $\mathrm{T}$.

Following the normalized cross-covariance function, we calculated the cross-correlation function (CCF), which represents a set of correlations between the time series $\mathrm{xt}+\mathrm{T}$ and the time series $\mathrm{yt}$ for lag values $\mathrm{T}=0, \pm 1, \pm 2$, and so on. The value of $r_{-} x y$ ranges from -1 to 1 . It is to note also that the cross-correlation function is not symmetric around zero, which means that $\mathrm{r}_{-} \mathrm{xy}(\mathrm{T}) \neq \mathrm{r} \_\mathrm{xy}(-\mathrm{T})$. When lag is negative $(T<0)$, the set of correlations refers to the correlation between the $\mathrm{x}$ time series at a time before $\mathrm{t}$ ( $\mathrm{x}_{-}$ $(\mathrm{t}-\mathrm{T})$ ), and the $\mathrm{y}$ time series at time $\mathrm{t}\left(\mathrm{y}_{-} \mathrm{t}\right)$. When the lag is positive $(\mathrm{T}>0)$, the set of correlations refers to the correlation between the $\mathrm{x}$ time series at a time after $\mathrm{t}\left(\mathrm{x} \_(\mathrm{t}+\mathrm{T})\right)$, and the $y$ time series at time $\mathrm{t}(\mathrm{y} \mathrm{t})$. When time lag equals

$$
r_{x y}=\frac{\sigma_{x y}}{\sigma_{x} \sigma_{y}}
$$

zero $(T=0)$, the value of cross-correlation equals the value of the Pearson correlation coefficient:

where $\sigma x y$ is the covariance between the observed time series $\mathrm{xt}$ and $\mathrm{yt}$, while $\sigma \mathrm{x}$ and $\sigma \mathrm{y}$ are their standard deviations. Significant correlation values suggest that the changes in one time series appear immediately following the changes in the other time series (Shin, 2017).

To present the results of cross-correlation analysis, we used a graphical representation of CCF using correlation plots. The $\mathrm{x}$-axis represents a time lag $(\mathrm{T})$, and the $\mathrm{y}$-axis represents the value of cross-correlation. Blue dotted lines (at Figures 2, 3, and 5) represent the approximate 95\% confidence intervals that serve as the threshold for identifying statistically significant cross-correlation values. To identify a potential significant correlation between lagged time series $\mathrm{x}$ and time series $\mathrm{y}$ at time $\mathrm{t}$, we examined the values of CCF for negative lag values $(T<0)$. In this case, when the cross-correlation is statistically significant, then the change in time series $x$ leads to the change in time series y after the period, determined by the lag $\mathrm{T}$, at which cross-correlation is significant (Shin, 2017).

Based on the cross-correlation analysis results between the observed time-series, we also examined possible dynamics of the observed time series. Thus, we finally conducted vector autoregression (VAR) analysis, which is an extension of well-known linear- and auto-regressions. When analyzing $\mathrm{k}$ time series, the VAR analysis allows predicting all $\mathrm{k}$ time series variables using a single model, instead of fitting $\mathrm{k}$ regression models individually. The VAR model is best presented as a system of multiple equations, in which there is one equation for each time series as a dependent variable, where the goal is to estimate each equation separately using the lagged values of all $\mathrm{k}$ time series as predictors (Hanck et al. 2019). Following the basic form of a VAR model (as suggested by Zivot and Wang, 2006), for the i-th time series in the VAR model, we can

$$
Y_{i, t}=\beta_{i 0}+\sum_{i=1}^{k} \sum_{j=1}^{T} \beta_{1 i, j} \cdot Y_{i, t-j}
$$

present the equation as:

where $\mathrm{k}$ represents the number of time series included in the model, $T$ denotes a time lag, and the $\beta$ s are estimated using ordinary least squares.

To fit the best model, we also had to estimate the optimal number of lags $(\mathrm{T})$, which defines a lag order of the VAR model. Here we used the Akaike's Information Criteria (AIC) and chose the specification that has the smallest value for AIC (as explained by Zivot and Wang, 2006). We also assessed the quality of the defined VAR model using F-test and its p-value, as well as the multiple R2, to identify the proportion of the variance explained by the model. Then, we estimated the proposed VAR model, in which the significance of the results was tested using a t-test. Finally, we used the estimated model to predict and present the future trends in labor productivity in the manufacturing sector, the number of industrial robot shipments, manufacturing employment, and manufacturing employees' education level change. 


\section{Results}

In comparison to previous studies, we decided to analyze data for one of the most robotized economies (the U.S.) $)^{3}$ and attempted to consider several of the most relevant indicators simultaneously, to show a concise and clear image of the performance of the manufacturing sector in light of the transformation to Industry 4.0. Specifically, as Essentra (2019) is suggesting, the U.S. is the leading market in Industry 4.0, while Schreiber in Essentra (2019) explains, "The U.S. government sees manufacturing as an engine for growth and we've seen increased research and development $(\mathrm{R} \& \mathrm{D})$ tax credits and lower corporate rates."

Table 1: Employment (in thousands) and output (billions of dollars) - companies from the manufacturing sector and industry as a whole in the U.S. (years 2008 to 2028) (U.S. Bureau of Labor Statistics, 2019a)

\begin{tabular}{|l|c|c|c|c|c|}
\hline & $\mathbf{2 0 0 8}$ & $\mathbf{2 0 1 8 / 2 0 0 8}$ & $\mathbf{2 0 1 8}$ & $\mathbf{2 0 2 8 / 2 0 1 8}$ & $\mathbf{2 0 2 8}$ \\
\hline Total Employment & $149,276.00$ & $7.88 \%$ & $161,037.70$ & $5.22 \%$ & $169,435.90$ \\
\hline Manufacturing Employment & $13,405.50$ & $-5.35 \%$ & $12,688.70$ & $-5.05 \%$ & $12,048.00$ \\
\hline Total Output & $28,909.50$ & $14.99 \%$ & $33,241.90$ & $20.47 \%$ & $40,045.30$ \\
\hline Manufacturing Output & $5,989.20$ & $2.42 \%$ & $6,134.00$ & $16.81 \%$ & $7,164.90$ \\
\hline
\end{tabular}

In Table 1, we present data on employment and outputs in companies from the manufacturing sector and in industry in general in the U.S. to answer our first research question. The data show that the employment in the U.S. grew at a compound annual growth rate (CAGR) of $0.7 \%$ from 2008 until 2018 in the industry as a whole, while in the manufacturing sector it declined at a CAGR of $0.5 \%$. Projections show that in the next decade we can expect CAGR growth of $0.5 \%$ in industry as a whole, while in manufacturing a continued decline of $0.5 \%$ is projected.

Furthermore, the data from Table 1 reveal that from 2008 to 2018 , the U.S. industrial output increased by $15.0 \%$ in general, while in manufacturing it increased only by $2.4 \%$. Considering the same (constant 2011 dollars) variable, from 2008 to 2018 , the CAGR of $1.3 \%$ in the industry as a whole was measured, while in the manufacturing sector it grew only by $0.2 \%$. From 2018 to 2028 , stronger CAGR growth of $1.7 \%$ in industry as a whole is expected, while in manufacturing only the increase of $1.4 \%$ is projected.

As a result, the percentage distribution among different sectors shows (U.S. Bureau data, 2019a) that the share of output from the manufacturing sector is decreasing, as it declined from $20.7 \%$ in 2008 to $18.5 \%$ in 2018 , and a further decline is projected in 2028 to $17.9 \%$. Similarly, the share of manufacturing employees declined from $9.0 \%$ to $7.9 \%$ (2008 vs. 2018 ), while further decline to $7.1 \%$ is expected in 2028 .

Data from Figure 1 answer our second research question, as they present the number of industrial robot shipments in the U.S., which grew at a CAGR of $11.3 \%$ from 2008 to 2018 (IFR, 2018b and 2019). As shown in Table 2 , the growth in the number of industrial robot shipments in the 2008-2018 period is significant, for which time explains $93.4 \%$ of the variation in growth.

In contrast, in the same period, employment in manufacturing declined at a CAGR of $0.5 \%$, and as shown in Table 2 the change in the number of employees in the 2008-2018 period is not significant. Additionally, time explains only $2.5 \%$ of the variation in the number of employees. Similarly, labor productivity in manufacturing grew at a CAGR of $0.8 \%$ from 2008 to 2018 , while the growth in labor productivity in this period is not significant and time explains only $6.7 \%$ of the variation in labor productivity growth.

We can observe the drop in both the number of industrial robot shipments as well as the employment in manufacturing in 2009 as compared to 2008, which can be attributed to the 2008-economic crisis. In the following years, from 2011 to 2018, we ascertain steady increases in both the number of industrial robot shipments and employment in manufacturing, but the increase in the latter was much less intense.

\footnotetext{
${ }^{3}$ In terms of industrial robot shipments, China led among individual countries, based on 36.5\% share in 2018 (1.4 percentage points less than in 2017), while the U.S. climbed from fourth to third place (behind Japan and Republic of Korea) in 2018, based on $21.6 \%$ y-o-y growth (IFR, 2019). The driver behind the continued growth of industrial robot shipments in the U.S. is the ongoing trend to automate production in order to strengthen the country's industry and to keep manufacturing production at home, or to bring it back home (IFR, 2018a). In 2018, the average global robot density of 99 industrial robots installed per 10,000 employees was measured in the manufacturing industry. With an average of 114 units, Europe is the region with the highest robot density, while the Americas the second with 99 units, followed by Asia/Australia with 91 units (IFR, 2019).
} 


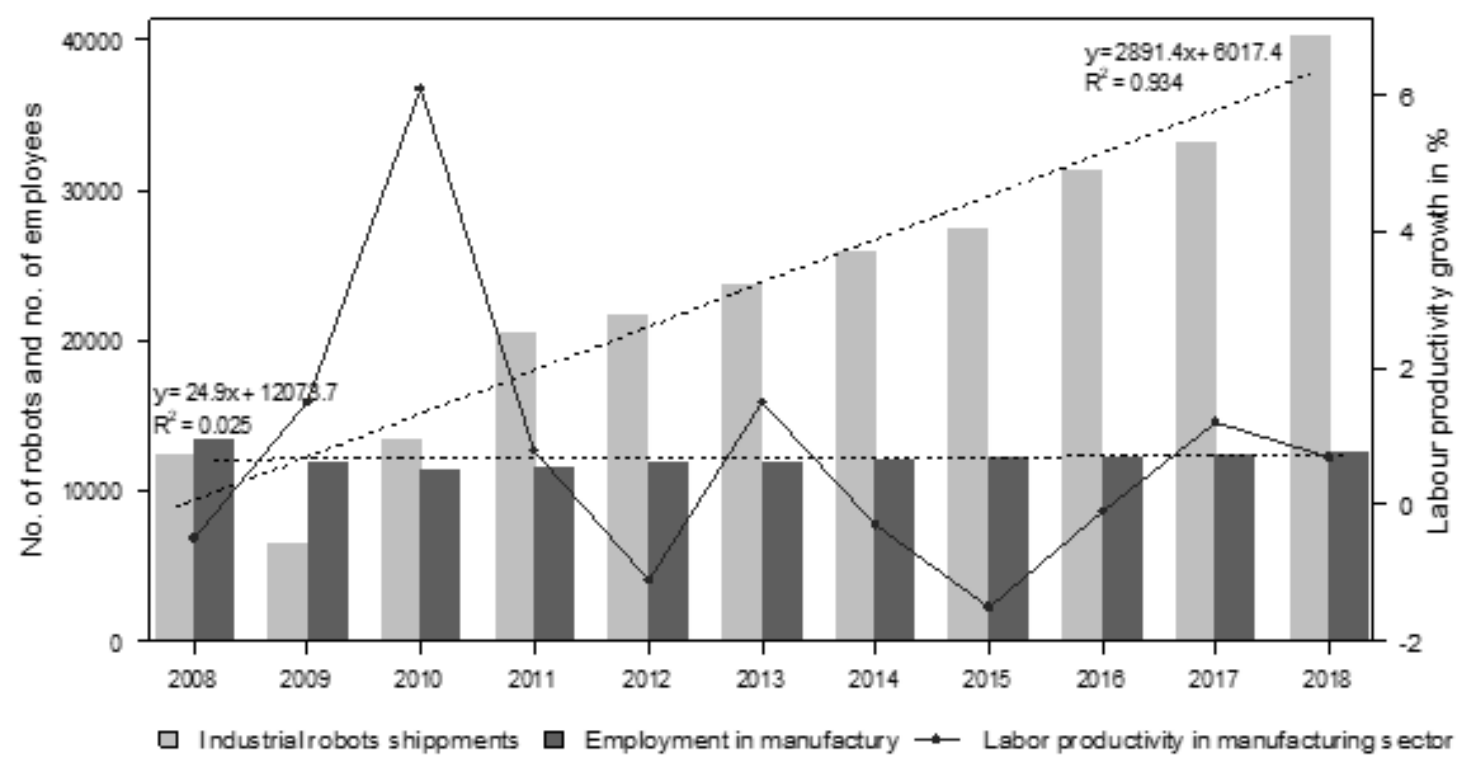

Figure 1: Number of shipped industrial robots and number of employees vs. labor productivity (percentage change from previous year) in the U.S. manufacturing sector (2008-2018) (IFR, $2018 b$ and 2019, U.S. Bureau of Labor Statistics, $2019 b$ and 2019c)

Table 2: Number of shipped industrial robots, number of employees and labor productivity (percentage change from previous year) in the U.S. manufacturing sector (2008-2018) as functions of time

\begin{tabular}{|c|c|c|c|c|c|c|c|}
\hline \multirow[b]{2}{*}{ RS } & \multirow[b]{2}{*}{ Estimate } & \multirow[b]{2}{*}{ Std. error } & \multicolumn{2}{|c|}{$t$-value } & \multicolumn{2}{|c|}{$\boldsymbol{F}$} & \multirow[b]{2}{*}{$R^{2}$} \\
\hline & & & statistic & $p$-value & statistic & $p$-value & \\
\hline Constant & $6017.3818^{* *}$ & 1744.9017 & 3.449 & 0.007 & \multirow{2}{*}{126.308} & \multirow{2}{*}{0.000} & \multirow{2}{*}{0.934} \\
\hline Time & $2891.3909^{* *}$ & 257.2717 & 11.239 & 0.000 & & & \\
\hline \multicolumn{8}{|l|}{ EMPL } \\
\hline Constant & $12073.7000^{* *}$ & 348.6529 & 34.630 & 0.000 & \multirow{2}{*}{0.234} & \multirow{2}{*}{0.640} & \multirow{2}{*}{0.025} \\
\hline Time & 24.8796 & 51.4061 & 0.484 & 0.640 & & & \\
\hline \multicolumn{8}{|l|}{ PROD } \\
\hline Constant & 1.7145 & 1.3463 & 1.273 & 0.235 & \multirow{2}{*}{0.650} & \multirow{2}{*}{0.441} & \multirow{2}{*}{0.067} \\
\hline Time & -0.1600 & 0.1985 & -0.806 & 0.441 & & & \\
\hline
\end{tabular}

** The estimate is significant at the 0.01 level.

Furthermore, labor productivity in manufacturing varied from one year to another (U.S. Bureau of Labor Statistics, 2019b), but we would like to emphasize that the situation was not improving. If we exclude direct impacts of the economic crisis starting in 2008, the labor productivity in manufacturing was very low, especially in the last eight years presented, in which the greatest year-over-year growth of $1.4 \%$ was recorded in 2013, and the strongest decline of $1.6 \%$ was measured in 2015 .

To answer our first (2.1) research sub-question, we used the cross-correlation analysis to test the association and potential impact of industrial robot shipments on employment and labor productivity in the manufacturing sector in the observed 2008-2018 period (Figure 2 and Figure $3)$.

Figure 2 presents the CCF for the number of industrial robot shipments and employment in manufacturing. The correlation between the observed time-series data (when time lag $=0$ years) shows weak positive association $(\mathrm{r}=$ 0.24 ), which means that immediately after the number of shipped robots increases, the employment in manufacturing increases too. However, significant correlation appears 
only at time lag $=-1$ year $(\mathrm{r}=0.60)$, indicating that an increase in the number of shipped robots more certainly leads to an increase in manufacturing employment about one year later. We can also support this finding with the calculation that $97.1 \%$ of the variation $(\mathrm{R} 2=0.971)$ in manufacturing employment is explained when predicting it using the one-year lagged number of shipped robots.

Number of industrial robots' shipments \& Employment in manufactury

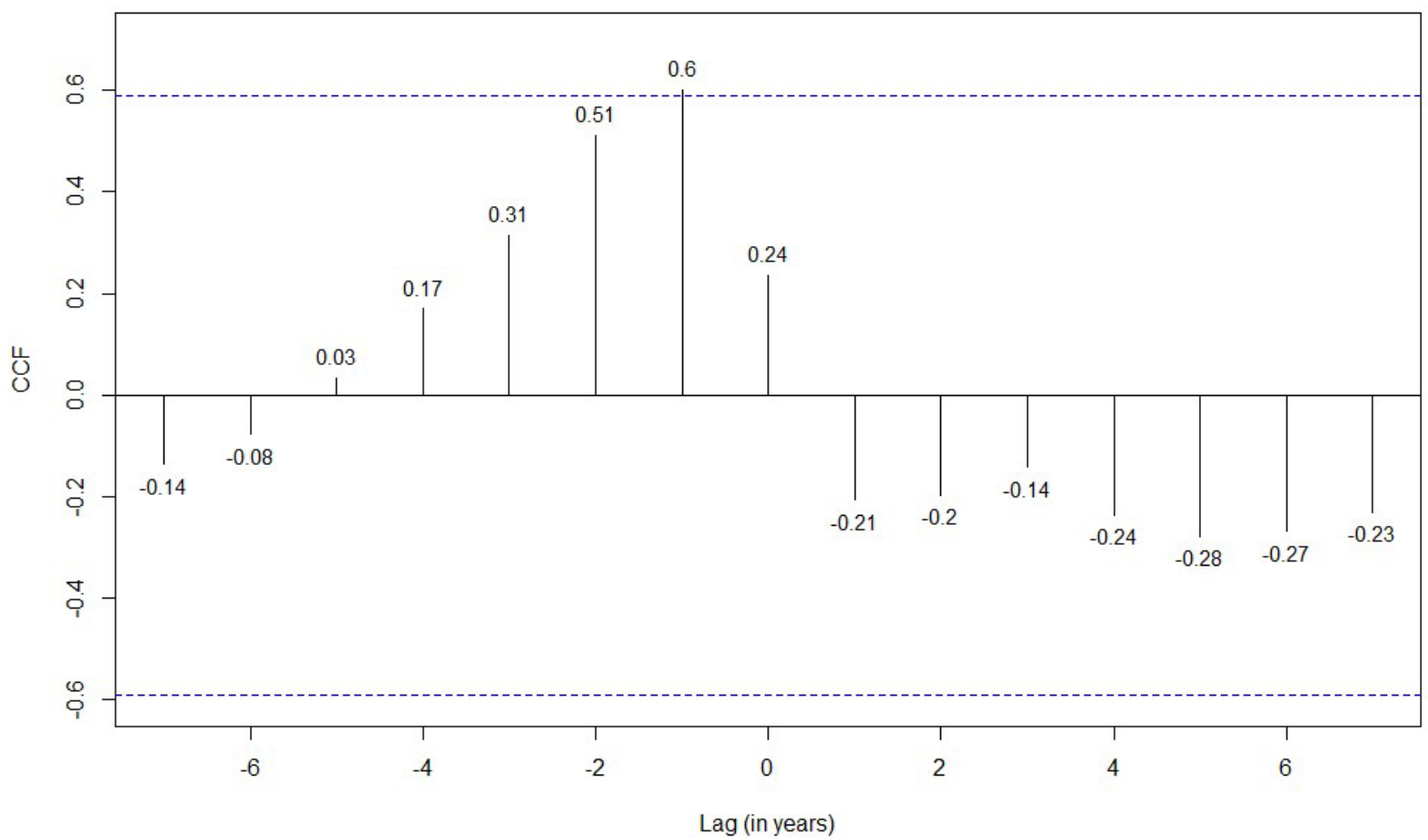

Figure 2: Cross-correlation function (CCF) for the number of industrial robot shipments and employment in manufacturing in the U.S. in the observed 2008-2018 period

Figure 3 presents the CCF for the number of industrial robot shipments and labor productivity in the manufacturing sector in the observed 2008-2018 period. The correlation between the observed time-series data (when time lag $=0$ years) shows moderate negative association ( $\mathrm{r}$ $=-0.34$ ), which means that immediately after the number of shipped robots increases, the labor productivity in the manufacturing sector decreases. Moreover, at time lag = 1 year the negative correlation becomes even stronger $(r=$ -0.54) indicating that an increase in the number of shipped robots about one year later leads to an even stronger decrease in labor productivity. Only after three years (when time lag $=-3$ years) the correlation turns out to be positive but very weak $(r=0.15)$. However, it is noteworthy that in the presented CCF none of the correlations is statistically significant, which indicates that we have to recognize that the reasons behind weak labor productivity growth can be several and different and not only related to the introduction of robots. We can also support this finding with the calculation that only $11.6 \%$ of the variation $(\mathrm{R} 2=0.116)$ in labor productivity is explained when predicting it using the number of shipped robots.

Data from Figure 4 answers our third research question, presenting the number of industrial robot shipments in the U.S., and the employees' education level ${ }^{4}$ in the manufacturing sector expressed in proportions (IFR, $2018 \mathrm{~b}$ and 2019, WB, 2019). The proportion of manufacturing employees with lower levels of education (i.e., below upper secondary and upper secondary) is steadily decreasing, while the proportion of manufacturing employees with the highest level of education (i.e., tertiary) is constantly increasing. In 2015 , the proportion of man-

${ }^{4}$ To present a level of education the source (WB, 2019) uses the term "adults"' for employees aged 24-64, while in our paper we use simply "employees' education level". 


\section{Number of industrial robots' shipments \& Labour productivity in manufacturing sector}

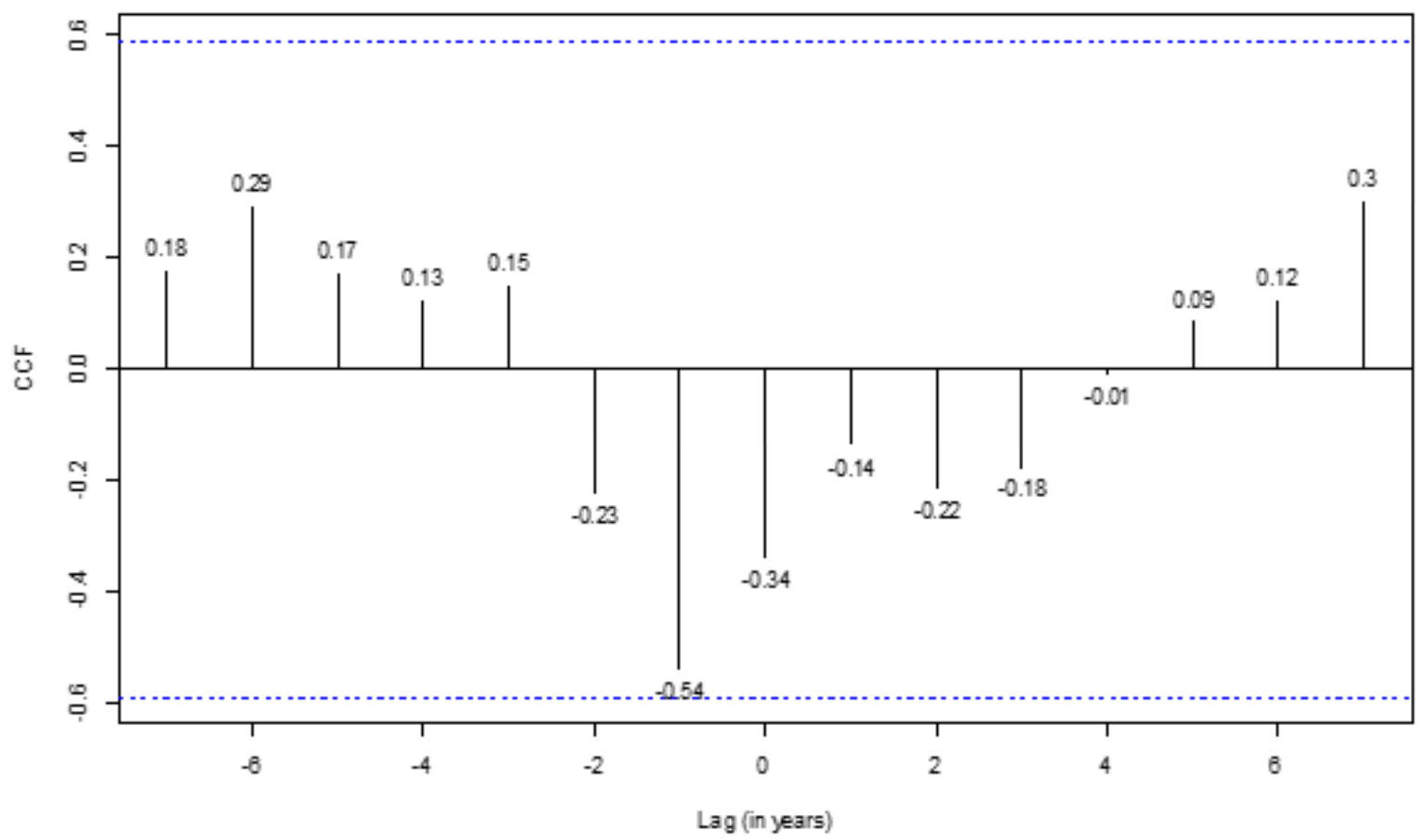

Figure 3: Cross-correlation function (CCF) for the number of industrial robot shipments and labor productivity in manufacturing sector in the U.S. in the observed 2008-2018 period

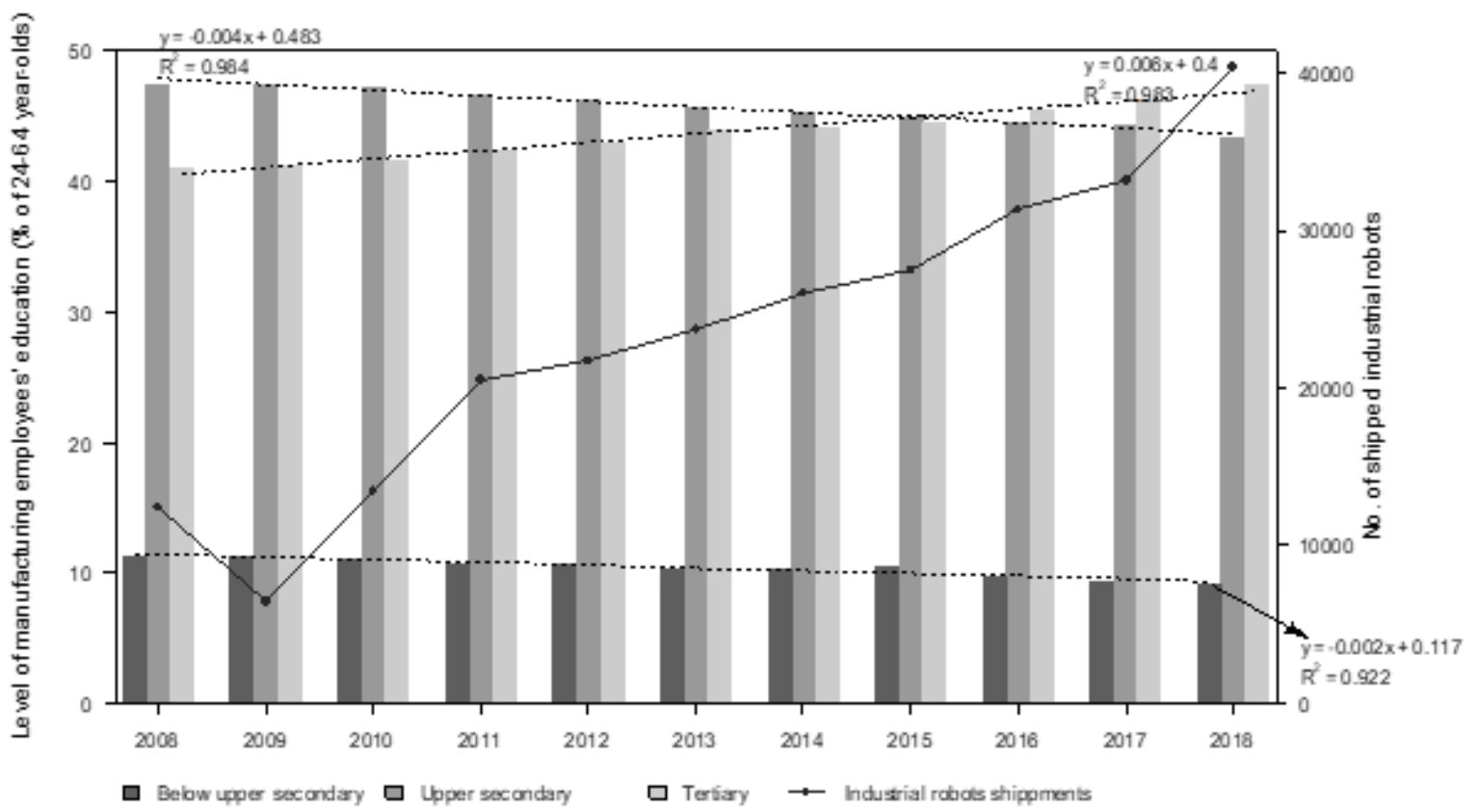

Figure 4: Number of shipped industrial robots vs. level of manufacturing employees' education (\% of 24-64-year-olds) in the U.S. in the observed 2008-2018 period (IFR, 2018b and 2019, WB, 2019) 
Table 3: Number of shipped industrial robots vs. level of manufacturing employees' education (\% of 24-64-year-olds) in the U.S. in the observed 2008-2018 period as functions of time

\begin{tabular}{|c|c|c|c|c|c|c|c|}
\hline \multirow[b]{2}{*}{ Below Upper secondary } & \multirow[b]{2}{*}{ Estimate } & \multirow[b]{2}{*}{ Std. Error } & \multicolumn{2}{|c|}{ t-value } & \multicolumn{2}{|c|}{$F$} & \multirow[b]{2}{*}{$R^{2}$} \\
\hline & & & statistic & p-value & statistic & $p$-value & \\
\hline Constant & $0.1169^{* *}$ & 0.0014 & 85.079 & 0.000 & \multirow{2}{*}{106.572} & \multirow{2}{*}{0.000} & \multirow{2}{*}{0.922} \\
\hline Time & $-0.0021^{* *}$ & 0.0002 & -10.323 & 0.000 & & & \\
\hline \multicolumn{8}{|l|}{ Upper secondary } \\
\hline Constant & $0.4833^{* *}$ & 0.0012 & 395.706 & 0.000 & \multirow{2}{*}{557.300} & \multirow{2}{*}{0.000} & \multirow{2}{*}{0.984} \\
\hline Time & $-0.0043^{* *}$ & 0.0002 & -23.607 & 0.000 & & & \\
\hline \multicolumn{8}{|l|}{ Tertiary } \\
\hline Constant & $0.3999^{* *}$ & 0.0019 & 211.100 & 0.000 & \multirow{2}{*}{515.646} & \multirow{2}{*}{0.000} & \multirow{2}{*}{0.983} \\
\hline Time & $0.0063^{* *}$ & 0.0003 & 22.708 & 0.000 & & & \\
\hline
\end{tabular}

** The estimate is significant at the 0.01 level.

ufacturing employees with the upper secondary and tertiary levels of education is nearly the same, but since 2016 the proportion of those with the tertiary level of education exceeds the proportion of those with the upper secondary level of education.

As shown in Table 3, for all three levels of education, the trends as functions of time are also significant, where time explains $92.2 \%, 98.4 \%$, and $98.3 \%$ of the variation in the below upper secondary, upper secondary and tertiary levels of education, respectively.

We are aware that the level of education depends on many factors, and it is growing evenly in most countries, regardless of the introduction of robots. Nonetheless, we decided to analyze the interrelation among the levels of education in manufacturing and robotization, since robotization requires more educated employees (Guoping et al., 2017; Lima, 2017; Lindeberg, 2018; Abramova and Grishchenko, 2020), which are able to supervise, install, reconfigure, etc. robots. We also wanted to determine if robots mostly replace jobs of the employees with the mid education levels (as stated by Davidow and Malone, 2014 and Chiacchio et al., 2018) or with the lowest one. In this regard, Figure 4 data indicate that when the number of industrial robot shipments increases, the education level of manufacturing employees also increases, while the stronger decline of manufacturing employees is measured among those with upper secondary education, not among those with below upper secondary education.

Since there is an obvious trend in the change ${ }^{5}$ of manufacturing employees' level of education as compared to the number of robot shipments, we also tested the association between the two indicators using the cross-correlation analysis (Figure 5) to answer our second (3.1) sub research question, although we emphasize that we keep in mind that the mutual association between the two observed variables is not decisive.

The correlation between the observed time-series data (when time lag $=0$ years) shows significant and very strong positive correlation $(\mathrm{r}=0.96)$, which means that immediately after the number of shipped robots increases, the level of manufacturing employees' education also increases. The data also show significant correlation at time lag $=-1$ year $(\mathrm{r}=0.75)$ indicating that one year after the number of shipped robots increases, the manufacturing employees' education level still increases. In contrast, a significant correlation also appears at time lag $=1$ year $(\mathrm{r}$ $=0.69$ ), which implies that the increase in manufacturing employees' education level can be observed even one year before the number of shipped robots increases.

Although we have emphasized that it is not decisive that growth in the level of education can be attributed to the introduction of robots, the fact that $92.5 \%$ of the variation $(\mathrm{R} 2=0.925)$ in manufacturing employees' education level change is explained by the number of industrial robot shipments is self-evident.

Following the findings presented above, there is a tendency of association between labor productivity, employment and industrial robot shipments on the one hand, and the education level and industrial robot shipments on the other.

${ }^{5}$ Here, we calculated the change in education level as the difference between the proportion of manufacturing employees with below upper secondary level of education and the proportion of those with tertiary level of education. 
Number of industrial robots' shipments \& Change in manufacturing employees' educational level

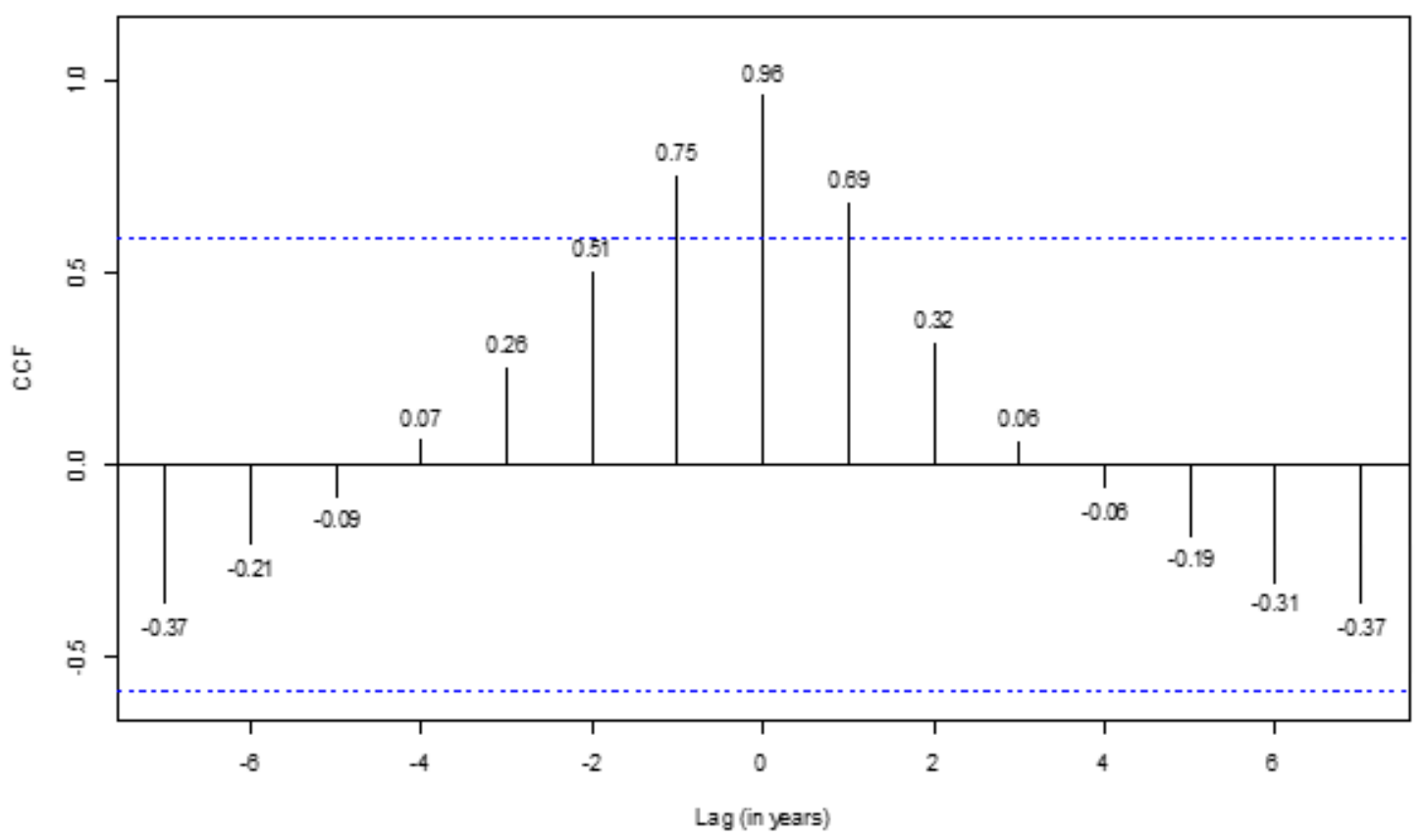

Figure 5: Cross-correlation function (CCF) for the number of industrial robot shipments and change in manufacturing employees' education level in the U.S. in the observed 2008-2018 period

Hence, we generated a time-series using multiple variables, i.e., labor productivity in the manufacturing sector (PROD), industrial robot shipments (RS), employment in the manufacturing sector (EMPL), and change in the education level of manufacturing employees (EDU_ch). To eliminate the influence of different measurement scales of the observed variables, we used the standardized time-series data from 2008 to 2018 and conducted VAR analysis to predict multiple time series variables, using a sin-

$$
\begin{gathered}
P^{2} O D_{t}=\beta_{10}+\beta_{11} P R O D_{t-1}+\beta_{12} R S_{t-1}+\beta_{13} E M P L_{t-1}+\beta_{14} E D U_{-} c h_{t-1} \\
R S_{t}=\beta_{20}+\beta_{21} P R O D_{t-1}+\beta_{22} R S_{t-1}+\beta_{23} E M P L_{t-1}+\beta_{24} E D U_{-} c h_{t-1} \\
E M P L_{t}=\beta_{30}+\beta_{31} P R O D_{t-1}+\beta_{32} R S_{t-1}+\beta_{33} E M P L_{t-1}+\beta_{34} E D U_{-} c h_{t-1} \\
E D U_{-} c h_{t}=\beta_{40}+\beta_{41} P_{R O D_{t-1}}+\beta_{42} R S_{t-1}+\beta_{43} E M P L_{t-1}+\beta_{44} E D U_{t-1}
\end{gathered}
$$

gle model. Here, we used the AIC criteria to find the best model and to estimate the optimal number of lags for the time-series. Based on the 1-ordered time lag is the most optimal; therefore, we estimated the vector autoregression model specifying the time lag order as 1 .

Using VAR model analysis, we were looking to estimate four autoregression equations, one for each of the observed variables:

The results are presented in Table 4 and Table 5; when combined with the trends presented in Figure 6, they an- swer our last research question: "What are the expected future interrelated developments of manufacturing labor productivity, employment, education level, and robotization?"

When predicting each of the observed variables, the VAR models are statistically significant $(p<0.05)$. It also turns out that the strength of the analyzed relationships is relatively high. Namely, the values of the R2 range from 0.865 and 0.986 , which indicates that at least $86.5 \%$ of the variation in dependent variables is caused by independent variables in the VAR model. 
Table 4: Summary of vector autoregression models

\begin{tabular}{|c|c|c|c|c|c|}
\hline \multirow[b]{2}{*}{ Model } & \multicolumn{3}{|c|}{$\boldsymbol{F}$} & \multirow{2}{*}{$R^{2}$} & \multirow{2}{*}{ Adjusted $R^{2}$} \\
\hline & statistic & $d f$ & $p$-value & & \\
\hline $1^{\mathrm{a}}$ & 8.04 & 4,5 & 0.0210 & 0.865 & 0.758 \\
\hline $2^{b}$ & 51.89 & 4,5 & 0.0003 & 0.977 & 0.958 \\
\hline $3^{c}$ & 86.85 & 4,5 & 0.0000 & 0.986 & 0.975 \\
\hline $4^{d}$ & 53.21 & 4,5 & 0.0003 & 0.977 & 0.959 \\
\hline
\end{tabular}

a Dependent variable: PROD; Independent variables: RS, EMPL, EDU_ch. b Dependent variable: RS; Independent variables: PROD, EMPL, EDU_ch. c Dependent variable: EMPL; Independent variables: PROD, RS, EDU_ch. d Dependent variable: EDU_ch; Independent variables: PROD, RS, EMPL.

Table 5: Vector autoregression coefficients for the estimated models

\begin{tabular}{|c|c|c|c|c|}
\hline PROD & Estimate & Std. error & $t$-value & $p$-value \\
\hline Constant & 0.1296 & 0.1684 & 0.770 & 0.476 \\
\hline PROD $_{t-1}$ & -0.4119 & 0.2144 & -1.921 & 0.113 \\
\hline $\mathrm{RS}_{t-1}$ & $-3.7311^{* *}$ & 0.7378 & -5.057 & 0.004 \\
\hline $\mathrm{EMPL}_{t-1}$ & -0.0732 & 0.1995 & -0.367 & 0.729 \\
\hline EDU_ch ${ }_{t-1}$ & $3.3002^{* *}$ & 0.7790 & 4.237 & 0.008 \\
\hline \multicolumn{5}{|l|}{ RS } \\
\hline Constant & $0.2551^{*}$ & 0.0666 & 3.832 & 0.012 \\
\hline PROD $_{t-1}$ & -0.0139 & 0.0848 & -0.164 & 0.876 \\
\hline $\mathbf{R S}_{t-1}$ & 0.3589 & 0.2917 & 1.230 & 0.273 \\
\hline EMPL $_{t-1}$ & $-0.3196^{* *}$ & 0.0789 & -4.052 & 0.010 \\
\hline EDU_ch ${ }_{t-1}$ & 0.7051 & 0.3079 & 2.209 & 0.071 \\
\hline \multicolumn{5}{|l|}{ EMPL } \\
\hline Constant & $-0.1039^{*}$ & 0.0366 & -2.839 & 0.036 \\
\hline PROD $_{t-1}$ & 0.0219 & 0.0466 & 0.470 & 0.658 \\
\hline $\mathbf{R S}_{t-1}$ & 0.4054 & 0.1603 & 2.528 & 0.053 \\
\hline $\mathrm{EMPL}_{t-1}$ & $0.1280^{*}$ & 0.0434 & 2.952 & 0.032 \\
\hline EDU_ch ${ }_{t-1}$ & 0.3381 & 0.1693 & 1.998 & 0.102 \\
\hline \multicolumn{5}{|l|}{ EDU_CH } \\
\hline Constant & 0.3120 & 0.0646 & 4.832 & 0.005 \\
\hline PROD $_{t-1}$ & -0.0279 & 0.0822 & -0.339 & 0.748 \\
\hline $\mathbf{R S}_{t-1}$ & -0.0814 & 0.2830 & -0.288 & 0.785 \\
\hline EMPL $_{t-1}$ & -0.0725 & 0.0765 & -0.948 & 0.387 \\
\hline EDU_ch ${ }_{t-1}$ & $1.1782^{*}$ & 0.2987 & 3.944 & 0.011 \\
\hline
\end{tabular}

** The estimate is significant at the 0.01 level.

* The estimate is significant at the 0.05 level. 
In the first model, when estimating the equation for labor productivity, the first time lag of industrial robot shipments and the first time lag of change in education level for manufacturing employees are statistically significant, which indicates that labor productivity significantly drops one year after the number of industrial robot shipments increases. Furthermore, the results also show that the increase in the educational level leads to a significant increase in labor productivity one year later. It also turns out that the first time lag of labor productivity in the manufacturing sector and the first time lag of the number of employees in manufacturing has some impact on labor productivity, although their impact is not statistically significant.
In the second model, when estimating the equation for the number of industrial robot shipments, the first time lag of the number of employees in manufacturing is statistically significant. This finding indicates that the increase in the number of employees in manufacturing has a negative influence on the number of industrial robot shipments one year later.

In the third model, when estimating the equation for employment in manufacturing, the first time lag of employment in manufacturing is statistically significant. In the last model, when estimating the equation for the change in education level for manufacturing employees, the first time lag of the change in education level for manufacturing employees is statistically significant.

\section{Forecast from VAR model}

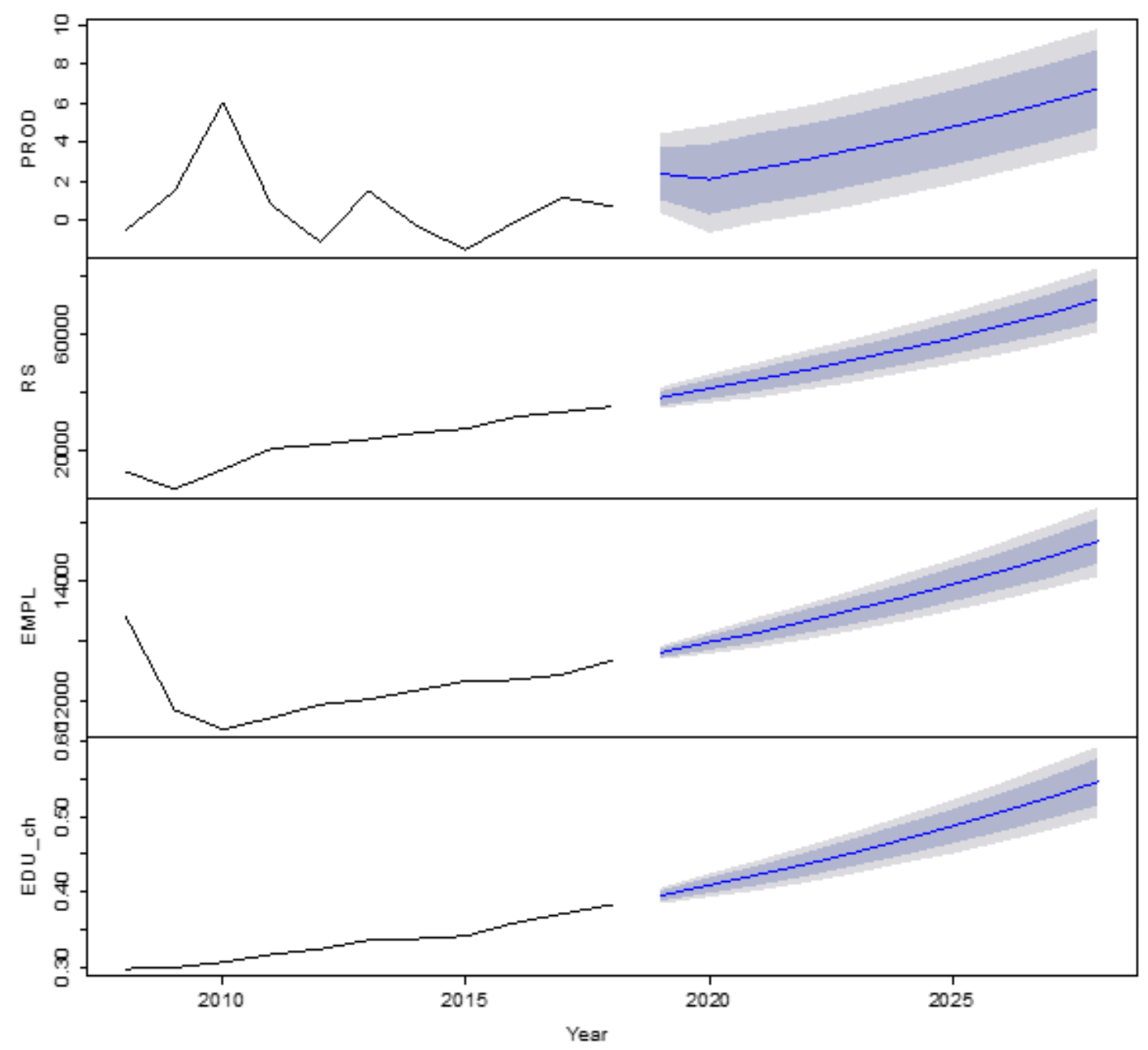

Figure 6: Predicted values for U.S. labor productivity (PROD), industrial robot shipments (RS), number of employees (EMPL) and change in employees' education level (EDU_ch) in manufacturing vs. industrial robot shipments (RS) based on VAR model (2008-2018 historical, 2019-2028 predicted) 
Following the estimated VAR models, we have also conducted the predictions for the future, which are presented in Figure 6. The left side of the figure shows the actual data for the observed 2008-2018 period, and the right side represents the predictions for the next 10-year period based on each autoregression equation. The predicted values for each individual time-series variable are presented as lines, and the shaded areas represent $80 \%$ and $95 \%$ confidence intervals thereof.

The results show that in the coming 10-year period, we can expect an increase in all of the observed variables. Accordingly, although the number of industrial robot shipments will increase, we can also expect a growth in the number of employees in the manufacturing sector with higher levels of education as compared to 2018. Consequently, labor productivity in the manufacturing sector will increase as well. These calculations project a bright future, which is in contrast to (for example) the U.S. Bureau of Labor of Statistics (2019a) data presented in Figure 1. Specifically, Figure 1 data project employment decline of $5.05 \%$ in manufacturing over the forecasted period (2028/18). Nonetheless, in case of significant economic situation changes in the forecasted decade, the future might not be as bright as predicted in Figure 6 .

\section{Discussion}

It is widely accepted that the current transition to Industry 4.0 requires significant and also long-term investments in company resources, while new technological opportunities change the performance of industrial enterprises and offer possibilities for increased profits and labor productivity. Nonetheless, besides investments in technology, investments in workers are also required. New employee profiles have to upgrade their skills all the time and have to be able to co-operate and work together with robots that take over traditional jobs within industry.

In this paper, we have attempted to provide clearer insight into the current developments within Industry 4.0 transformation, while our motivation was also to determine when (if) can we expect better impacts of investments in robotization, based on analysis of recent economic and social indicators for the manufacturing sector.

Answers and reflections are given to our research questions below:

1) How has the employment and output changed in the manufacturing sector in relation to the industry as a whole?

During the transition to Industry 4.0, U.S. manufacturing output has barely grown, while the number of employees decreased (Table 1). Having these findings in mind, the observed significant investments in the multipurpose robots in the U.S. (Figure 1) did not prevent manufacturing output share decline within industries, while they also lead to the reduction of manufacturing employees' share within industries.
Simpler tasks with lower required qualifications are taken by machines, robots. However, we have to keep in mind that robots can be extremely helpful in workplaces with difficult conditions and where the possibility of health problems occurs. Nonetheless, since people cannot compete with robots in many things (power, etc.), we agree with Dyer et al. (2010) that creativity will be one of the most sought-after talents in the future. Besides creativity, reasoning, adaptability, emotional intelligence, moral acting, critical thinking, problem solving, decision making, and similar, are the human qualities that will continue to gain importance. Thus, both now and in the future, there will be a constantly growing need for new knowledge and competences, and thus the place for human workers.

2) What were the impacts of robotization on employment and labor productivity in manufacturing during the period of entrance to Industry 4.0 ?

As the number of industrial robot shipments in the U.S. grew from 2008 to 2018, employment in manufacturing declined in 2018 vs. 2008 (Figure 1). Nonetheless, employment in manufacturing declined year-on-year only in 2009 and 2010, which can be attributed to the 2008-economic crisis, while in the period from 2011 to 2018 it was steadily increasing, although much less intense, as the industrial robot shipments.

Figure 1 data also present unexpectedly low labor productivity growth in the U.S. manufacturing sector, compared to robust growths of robots' shipments, especially in the last eight years, and as such they support the claims of Josefsson in Lindeberg (2018), that robots are now everywhere, except in productivity statistics.

For this reason, we must agree with Guoping et al. (2017) that government has to play a catalytic and supervisory role in processes of industry transformation and to accelerate and simultaneously guarantee proper development. Namely, the agitations over Industry 4.0, in which people who are replaced by robots have to be considered, and the preparation of the new national and transnational policies for sustainable industry development must be stimulated. Otherwise, as robots are becoming less expensive and more capable, they might replace many human workers, while unemployment could grow to meet the conditions for social crisis (even a social storm, as claimed by Johannessen, 2018).

2.1) How is the impact of robotization reflected in employment and labor productivity in manufacturing?

To answer this research question, we used the cross-correlation analysis to test the association and potential impact of industrial robot shipments on employment and labor productivity in the U.S. manufacturing sector in the observed 2008-2018 period (Figure 2 and Figure 3).

The correlation between the observed time-series data (when time lag $=0$ years) presented in Figure 2 shows a weak, positive association, which means that immediately after the number of shipped robots increases, the employment in manufacturing increases too. However, significant 
correlation appears only at time lag $=-1$ year, indicating that an increase in the number of shipped robots more certainly leads to an increase in manufacturing employment about one year later. We also were able to support this finding with the calculation that $97.1 \%$ of the variation in manufacturing employment is explained when predicting it using the one-year lagged number of shipped robots.

In contrast, the correlation between the observed time-series data (when time lag $=0$ years) presented in Figure 3 shows a moderate, negative association, which indicates that immediately after the number of shipped robots increases, the labor productivity in manufacturing sector decreases. Moreover, at time lag $=-1$ year the negative correlation becomes even stronger, implying that an increase in the number of shipped robots about one year later leads to an even stronger decline in labor productivity. Only after three years did the correlation turn positive, but very weak. However, it is to be noted that in this calculation none of the correlations is statistically significant, which indicates that we have to recognize that the reasons behind weak labor productivity growth can be several and different and not only related to the introduction of robots. We can also support this finding with the calculation that only $11.6 \%$ of the variation in labor productivity is explained when predicting it using the number of shipped robots. Thus, our research results cannot firmly support either the advocates of contemporary productivity paradox (Josefsson in Lindberg, 2018; Lakshmia and Bahlib, 2020), the positive claims of IFR (2017) "robots increase productivity" nor Cséfalvay's claim (2020) "Today in the literature a new consensus is emerging that adoption of industrial robots considerably increases productivity and contributes significantly to economic growth."

3) How did the employees' education level change during the period of manufacturing entrance to Industry 4.0?

We determined that the proportion of manufacturing employees with lower levels of education (i.e., below upper secondary and upper secondary) is steadily decreasing, while the proportion of manufacturing employees with the highest level of education (i.e., tertiary) is constantly increasing (Figure 4) and follows the robot shipment growth. We also determined that in the past researched period in the U.S., robots more likely replaced employees with the mid education levels (as stated by Davidow and Malone, 2014 and Chiacchio et al., 2018), since the stronger decline in the number of manufacturing employees was measured among those with upper secondary education, not among those with below upper secondary education.

Despite the above-indicated findings, we are aware that the level of education in manufacturing depends on many factors, not only on the introduction of robots. Nonetheless, robotization requires more educated employees (as suggested by Guoping et al., 2017; Lima, 2017; Lindeberg, 2018; Abramova and Grishchenko, 2020).

3.1) Is the impact of industry robotization reflected in the change of education level of employees in manufac- turing?

The correlation between the observed time-series data (when time lag $=0$ years), presented in Figure 5, reveals significant and very strong positive correlation, which means that immediately after the number of shipped robots increases, the level of manufacturing employees' education also increases. The data also show significant correlation at time lag $=-1$ year, indicating that one year after the number of shipped robots increases, the manufacturing employees' education level still increases. In contrast, significant correlation appears at time lag $=1$ year as well, implying that the increase in manufacturing employees' education level can be observed even one year before the number of shipped robots increases. Following these findings, we assume that the introduction of robots to the work process is at least three-fold, since a year before, in the same year and in the year after the investments in new robots in manufacturing, the employees' education increases at a significant level.

We nonetheless emphasize that the introduction of robots is not decisive for the level of education change, but the calculations show that $92.5 \%$ of the variation in manufacturing employees' education level change is explained by the number of industrial robots' shipment. From this point of view, the results support the claims that robotization tends to require higher educated workers (Guoping et al., 2017; Lima, 2017; Lindeberg, 2018; Abramova and Grishchenko, 2020).

4) What are the expected future interrelated developments of manufacturing labor productivity, employment, education level and robotization?

Based on the estimated VAR models (Figure 6), we predict positive developments in the U.S. manufacturing sector. Bearing in mind the presented calculations, it might be anticipated, that the U.S. has now finally arrived at the turning point within the Industry 4.0 period, after a period of negative trends of employment and labor productivity, which was the impact of country's entrance into Industry 4.0.

The forecasted growth in manufacturing employment, labor productivity, education, coexistent with the robot shipment growth, suggests that outlined negative trends of the number of employees and labor productivity in the researched period were only temporary, and we believe that was due to the lack of opportunity and knowledge on how to exploit robotization for the maximum efficiency. These findings oppose the U.S. Bureau of Labor of Statistics (2019a) data presented in Table 1 and also disagree with the claims of other authors (e.g., Compagnucci et al., 2019).

We emphasize that the projected positive future developments are expected for the U.S., while the same could also hold for most other developed countries in terms of Industry 4.0 adoption, as the calculations were made based on data for the U.S., which are one of the most robotized economies, according to IFR (2019). Nonetheless, in case 
of significant economic changes in the forecasted period (e.g., impact of current coronavirus pandemic (COVID-19), the future might not be as bright as projected in Figure 6.

Especially when analyzing and predicting such complex and impactful trends of economic and social stability, it is necessary to consider different factors and models, although projections are usually made based on a single observed variable. For this reason, we used VAR analysis, which allows predicting several time series variables using a single model. Although this analytical technique enables a more advanced forecasting approach than, for example, a simple linear regression method, it still assumes that the trend growths in the analyzed time series are all linear, which is also reflected in the predictions we made for the coming 10-year period. However, we recognize that unexpected events, such as the current coronavirus pandemic, also cause changes and cyclical trends in the studied indicators. As shown on the left side of Figure 6, the past trends of the economic indicators used are more or less non-linear, which is the most obvious in case of labor productivity, whereas in the case of the number of employees the trend is relatively stable. In this regard, it is proposed for future research that the linear predictive approach using VAR modeling is done on the transformed time series data (we can use, e.g., logarithmic or power transformations), since the transformations may inhibit greater fluctuations and improve linearity in non-linear time series (Shumway $\&$ Stoffer, 2017). Future research could furthermore use some other approaches, which allow analyzing non-linear multiple time series, e.g., non-linear VAR models (as described by Kilian \& Lütkepohl, 2017) or even VAR neural network models (as described by Yasin et al., 2018), which allow the analysis of non-linear time series without their prior transformation.

There are also other limitations of our research, which are suggested to be addressed in future research, such as analyzing a longer period, which could lead to more accurate statistical calculations and forecasts. In contrast, since our focus was on Industry 4.0, it would not make any sense to analyze a longer research period.

In future research, however, we recommend a comparison of the U.S. market with other countries (considering different demographic structure, etc.), and other details about the robot shipments are advised to be analyzed (e.g., their value, type, application etc.), as this would provide additional insight into the impacts of transformation to Industry 4.0. In light of the current coronavirus pandemic, which significantly changed the criteria and approach to robotization, it would be especially interesting to analyze how manufacturing companies already equipped with Industry 4.0 technology and robots will overcome the situation in comparison with other "lagging" companies. Since robots can work in surroundings harmful for human health, they should have a major advantage; nonetheless, generally decreased demand for manufactured goods most likely also has a negative impact on them.

\section{Conclusion}

During the transition to Industry 4.0, the manufacturing output, as well as the number of employees in manufacturing and labor productivity, have barely grown in the U.S. (see Table 1 and Figure 1). Nonetheless, our projections for the next decade (Figure 6) project brighter developments; for this reason, we support advocates of the development and use of AI and robots (as Wilson, 2017 and Hendler, 2017) in manufacturing. The future is in cooperation between robots and human. This partnership can bring prosperity and increased labor productivity, which is expected within a future global economy.

However, it is self-evident that people must maintain their decisive role in work processes; otherwise, robots might replace human workers, which would lead to even greater social inequity and consequent crisis. One can ask: "How can Sophia get human rights (Saudi Arabia citizenship), but I can't keep my job to maintain basic human dignity?" For this reason, new strategic directions are required, in which the humanization of industry must be highlighted as the most important. This implies that the transformation of industry has to be planned sustainably, due to the possible significant negative impact on society as a whole. For this reason, there is a constant need to investigate the impacts of industrial development, since the changes in society are much slower than the changes in technology.

The data we used for our research showed that there is still room for a human contribution in industry. Specifically, based on the VAR model, in the coming 10-year period, we can expect an increase in all of the observed variables. Projections thus show that while the number of industrial robot shipments will increase, we can also expect a growth in the number of employees in the manufacturing sector with increasing level of education, and the growth of labor productivity in the U.S. manufacturing sector. These calculation results are contrary to certain data and findings we present in our paper (e.g. U.S. Bureau of Labor of Statistics (2019a), Acemoulgu and Restrepo (2017), Glaser and Molla (2017), Josefsson in Lindeberg (2018), Lakshmia and Bahlib (2020), while they support findings from the IFR (2017), the UK Parliament (2018), and Cséfalvay (2020), among others. However, as already mentioned, in case of any disruption or changed circumstances, the calculated indicators for the future might change. Nonetheless, since the transition to Industry 4.0 has a major impact on increasing demands for new knowledge about technologies and production processes, at least a part of our modelled predictions should hold.

Especially now, at the "turning point" of the U.S. man- 
ufacturing sector, as indicated by our calculations, workers must focus on other tasks: those enabling the optimization of work processes, including control, analytics and regulation, while emphasis must also be on the effective communication, creativity and problem-solving acting. Here, the opportunity for an increased role of human workers should appear, while a higher degree of reasoning, flexibility, reliability, problem-solving acting, moral responsibility, and fast learning will be expected from the employees. According to Essentra (2019), for example, there is a current lack of the right workforce composition and the skill sets needed for the future; the skills U.S. manufacturers are most lacking are technology and computer skills, problem-solving ability, design engineering and mathematics, claiming "U.S. manufacturers are currently more concerned about how to attract and upskill workers rather than making plans to let them go."

Among the above-mentioned challenges and opportunities in the field of industry robotization, the economic and social sustainability of production requires the integration of human and technology. As Harper (2019) explains, a human-computer interaction perspective can help define interactions between $\mathrm{AI}$ and users that can enhance rather than substitute creativity. The new step in industry development - Industry 5.0 - should therefore focus primarily on human and robot engagement and the integration of human knowledge, creativity, intuition, skills, experience, etc. within robotized production. Moreover, Industry 5.0 should give reasons for human presence in industrial processes, but in forms based on the changed staffing requirements of modern production, including the ability to co-operate with robots.

Thus Industry 5.0 is supposed to change robots from programmable machined into ideal human companions, commonly termed as "cobot", that will already know, or quickly learn, what to do (Nahavandi, 2019). Although the prediction of Industry 5.0 is currently questionable, further industry transition should be regulated and oriented towards the integration of the virtual and the physical, considering the changed role of qualified workers and the newly established social responsibility of robots. Accordingly, we conclude that there is a need for increased awareness about the consequences of the transformation to Industry 4.0 , which calls for new policies for industry's economic and social sustainability, considering the specifics and labor (surplus or scarcity (Vermeulen, 2020) demands of individual economies and industrial sectors.

\section{Literature}

Abramova, N., \& Grishchenko, N. (2020). ICTs, Labour Productivity and Employment: Sustainability in Industries in Russia. Procedia Manufacturing, 43, 299-305. https://doi.org/10.1016/j.promfg.2020.02.161
Acemoglu, D., \& Restrepo, P. (2017). Robots and jobs: Evidence from US labor markets. Retrieved from https:// www.nber.org/papers/w23285

Bogataj, D., Battini, D., Calzavara, M., \& Persona, A. 2019. The Response Latency in Global Production and Logistics: A Trade-off between Robotization and Globalization of a Chain. Procedia Manufacturing. 39, 1428-1437. https://doi.org/10.1016/j.promfg.2020.01.309

Bossemann, J. (2016). Top 9 ethical issues in artificial intelligence. Retrieved from https://www.weforum.org/ agenda/2016/10/top-10-ethical-issues-in-artificial-intelligence/

Bottone, G. 2018. A tax on robots? Retrieved from http:// www.finanze.it/export/sites/finanze/it/.content/Documenti/Varie/dfwp3_2018.pdf

Chiacchio, F., Petropoulos, G., \& Pichler, D. (2018). The impact of industrial robots on EU employment and wages: A local labour market approach. Bruegel Working Paper, 2018/02, Bruegel, Brussels. Retrieved from https://www.econstor.eu/bitstre am/10419/207001/1/1028792522.pdf

Cho, J., \& Kim, J. (2018). Identifying Factors Reinforcing Robotization: Interactive Forces of Employment, Working Hour and Wage. Sustainability. 10(2), 490. https://doi.org/10.3390/su10020490

Compagnucci, F., Gentili, A., Valentini, E., \& Gallegati, M. (2019). Robotization and labour dislocation in the manufacturing sectors of OECD countries: a panel VAR approach, Applied Economics, 51:57, 6127-6138. https://doi.org/10.1080/00036846.2019.1659499

Cséfalvay, Z. (2020). Robotization in Central and Eastern Europe: catching up or dependence? European Planning Studies. 28(8), 1534-1553. https://doi.org/10.108 0/09654313.2019.1694647

Davidow, W. H., \& Malone M. C. (2014). What happens to society when robots replace workers? Harvard Business Review. December 10, 2014. https://hbr. $\operatorname{org} / 2014 / 12 /$ what-happens-to-society-when-robots-replace-workers

Dyer, J., Gregersen, H., \& Christensen., C. M. (2010). The innovator's DNA: mastering the five skills of disruptive innovators. Boston: Harvard Business Review Press.

EFFRA. (2016). Factories 4.0 and Beyond. Recommendations for the work programme 18-19-20 of the FoF PPP under Horizon 2020. Retrieved from http://www.effra. eu/sites/default/files/factories40_beyond_v31_public. pdf

Essentra. (2019). A guide to Industry 4.0 in the US. (23. Jan.). Retrieved from https://www.essentracomponents.com/en-us/news/guides/a-guide-to-industry-40in-the-us

Federal Reserve Economic Data (2018). Manufacturing Sector: Labor Productivity. Retrieved from https:// fred.stlouisfed.org/series/MPU9900063 
Frank, A., Dalenogare, L., \& Ayala, N. (2019). Industry 4.0 technologies: Implementation patterns in manufacturing companies. International Journal of Production Economics, 210, 15-26. https://doi.org/10.1016/j. ijpe.2019.01.004 .

Gianelle, C., Kyriakou, D., Cohen, C., \& Przeor, M., eds. (2016). Implementing Smart Specialization: A Handbook. Brussels: European Commission.

Glaser, A., \& Molla, R. (2017). The number of robots sold in the U.S. will jump nearly 300 percent in nine years. Job-stealing robots are steadily taking over America. Recode, 3 April 2017. Retrieved from https://www. recode.net/2017/4/3/15123006/robots-sold-america-growth-300-percent-jobs-automation

Guo F., Li, M., Qu, Q., \& Duffy, V. G. (2019). The Effect of a Humanoid Robot's Emotional Behaviors on Users' Emotional Responses: Evidence from Pupillometry and Electroencephalography Measures. International Journal of Human-Computer Interaction. 35(20), 1947-1959. https://doi.org/10.1080/10447318.2019.1 587938

Guoping, L., Yun, H., \& Aizhi, W. (2017). Fourth Industrial Revolution: Technological Drivers, Impacts and Coping Methods. Chinese Geographical Science. 2017, 27(4), 626-637. http://doi.org/10.1007/s11769017-0890-x

Hanck, C., Arnold, M., Gerber, A., \& Schmelzer, M. (2019). Introduction to Econometrics with R. Department of Business Administration and Economics, University of Duisburg-Essen, Essen, Germany. Retrieved from https://www.econometrics-with-r.org/

Harper, R. H. (2019). The Role of HCI in the Age of AI. International Journal of Human-Computer Interaction. 35(15), 1331-1344. http://doi.org/10.1080/10447318.2 019.1631527

Hendler, J. (2017). Fear Not, AI May Be Our New Best Partners in Creative Solutions. Retrieved from https:// www.techemergence.com/fear-not-ai-may-be-ournew-best-partners-in-creative-solutions-a-conversation-with-dr-james-hendler/

IFR (2017). The Impact of Robots on Productivity, Employment and Jobs, a positioning paper by the International Federation of Robotics, April 2017. Retrieved from https://ifr.org/img/office/IFR_The_Impact_of_ Robots_on_Employment.pdf

IFR (2018a). Executive Summary World Robotics 2017 Industrial Robots. Retrieved from https://ifr.org/downloads/press/Executive_Summary_WR_2017_Industrial_Robots.pdf

IFR (2018b). Executive Summary World Robotics 2018 Industrial Robots. Retrieved from https://ifr.org/downloads/press2018/Executive_Summary_WR_2018_Industrial_Robots.pdf

IFR (2019). Executive Summary World Robotics 2019
Industrial Robots. Retrieved from https://ifr.org/downloads/press2018/Executive\%20Summary\%20WR\%20 2019\%20Industrial\%20Robots.pdf

IFR (2020). Industrial Robots. Retrieved from https://ifr. org/industrial-robots

Jerman, A., Bertoncelj, A., Dominici, G., Pejić Bach, M., \& Trnavčević, A. (2020). Conceptual key competency model for smart factories in production processes. Organizacija, 53(1), 68-79. https://doi.org/10.2478/orga2020-0005

Johannessen, J. A. (2018). Automation, Innovation and Economic Crisis, Surviving the Fourth Industrial Revolution. London: Routledge.

Kilian, L., \& Lütkepohl, H. (2017). Structural Vector Autoregressive Analysis. Cambridge: Cambridge University Press.

Lakshmia, V., \& Bahlib, B. (2020). Understanding the robotization landscape transformation: A centering resonance analysis. Journal of Innovation \& Knowledge. 5(1), 59-67. https://doi.org/10.1016/j.jik.2019.01.005

Lima, P. U. (2017). Autonomous mobile robotics: a system perspective. New York: CRS Press.

Lindeberg, R. (2018). Robots Are Now Everywhere, Except in the Productivity Statistics. Bloomberg, 10. April 2018. Retrieved from https://www.bloomberg. com/news/articles/2018-04-10/robots-are-now-everywhere-except-in-the-productivity-statistics

Nahavandi, S. (2019). Industry 5.0-A Human-Centric Solution. Sustainability, 11 (16), 4371. https://doi. org/10.3390/su11164371

Putilo, N. V., Volkova, N. S., \& Antonova, N. V. (2020). Robotization in the Area of Labor and Employment: On the Verge of the Fourth Industrial Revolution. In: Popkova E. \& Sergi B. (eds.). Artificial Intelligence: Anthropogenic Nature vs. Social Origin. ISC Conference - Volgograd 2020. Advances in Intelligent Systems and Computing, 1100. Springer, Cham.

Rojko, K., \& Jelovac, D. (2018). Human role in factories of the future. Zbornik radova DIEC 2018. 1(1):165178. http://diec.ipi-akademija.ba/zbornici-radova/

Shin, Y. (2017). Time Series Analysis in the Social Sciences: The Fundamentals. University of California Press, Oakland, California.

Shumway, R. H., \& Stoffer, D. S. (2017). Time Series Analysis and Its Applications: With $R$ Examples (4th ed.). Springer, Cham, Switzerland.

Šimek, D., \& Šperka, R. (2019). How Robot/human Orchestration Can Help in an HR Department: A Case Study From a Pilot Implementation. Organizacija, 52(3). https://doi.org/10.2478/orga-2019-0013

UK Parliament (2018). Government response to House of Lords Artificial Intelligence Select Committee's Report on AI in the UK: Ready, Willing and Able? Retrieved from https:/www.parliament.uk/documents/ 
lords-committees/Artificial-Intelligence/AI-Government-Response2.pdf

U.S. Bureau of Labor Statistics. (2019a). Industry Output and Employment. Retrieved from https://www.bls. gov/emp/data/industry-out-and-emp.htm

U.S. Bureau of Labor Statistics. (2019b). Division of Major Sector Productivity. Retrieved from https://www. bls.gov/lpc/

U.S. Bureau of Labor Statistics. (2019c). All Employees, Manufacturing [MANEMP]. Retrieved from FRED, Federal Reserve Bank of St. Louis. https://fred.stlouisfed.org/series/MANEMP

Vermeulen, B., Pyka, A., \& Saviotti, P. P. (2020). Robots, Structural Change, and Employment: Future Scenarios. Springer. https://link.springer.com/content/ pdf/10.1007/978-3-319-57365-6_9-2.pdf

Wilson, M. (2017). Implementation of Robot System. New York: Butterworth-Heinemann.

World Bank (2019). World Bank open data. Economy \& Growth, https://data.worldbank.org/

World Economic Forum (2018a). Europe, Asia Lead the Way to the Factories of the Future. Retrieved from https://www.weforum.org/press/2018/09/europe-asialead-the-way-to-the-factories-of-the-future/

World Economic Forum (2018b). The Future of Jobs Report. Retrieved from http://www3.weforum.org/docs/ WEF Future of Jobs 2018.pdf

Yasin, H., Warsito, B., Santoso, R., \& Suparti, S. (2018). Soft Computation Vector Autoregressive Neural Network (VAR-NN) GUI-Based. E3S Web of Conferences, 73, p. 13008.
Zivot, E., \& Wang, J. (2006). Vector Autoregressive Models for Multivariate Time Series. In: Modeling Financial Time-Series with S-Plus, 385-429. New York: Springer.

Katarina Rojko is an Assistant Professor at the Faculty of Information Studies in Novo mesto, Slovenia. In research she focuses on information society and e-business, Industry 4.0., and also on innovative learning and teaching in higher education.

Nuša Erman is an Assistant Professor in the field of quantitative methods at the Faculty of Information Studies in Novo mesto, Slovenia. Her research work is focused on statistical methods and quantitative research, especially in the fields of information and social sciences.

Dejan Jelovac is a Professor of organizational sciences and business ethics at the Faculty of Information Studies in Novo mesto, Slovenia. His research interests include values and virtues in organizational culture, entrepreneurship, management and leadership, cross-cultural comparisons of organizational culture in business and public administration, challenges in multicultural business communication, and organizational development and corporate social responsibility in small and medium-sized business. 